\title{
Regional brain atrophy is related to social cognition impairment in multiple sclerosis
}

\author{
La atrofia cerebral regional se relaciona con el deterioro de la cognición social en \\ sclerosis múltiple
}

\author{
Tomas P. LABBE ${ }^{1,2}$, Cristian MONTALBA ${ }^{3}$, Mariana ZURITA³, Ethel Leslie CIAMPI ${ }^{4}$, Juan Pablo CRUZ ${ }^{5}$, \\ Macarena VASQUEZ ${ }^{4}$, Sergio URIBE ${ }^{3,5,6}$, Nicolás CROSSLEY,7, Claudia CÁRCAMO4
}

\begin{abstract}
Background: Multiple sclerosis exhibits specific neuropathological phenomena driving to both global and regional brain atrophy. At the clinical level, the disease is related to functional decline in cognitive domains as the working memory, processing speed, and verbal fluency. However, the compromise of social-cognitive abilities has concentrated some interest in recent years despite the available evidence suggesting the risk of disorganization in social life. Recent studies have used the MiniSEA test to assess the compromise of social cognition and have found relevant relationships with memory and executive functions, as well as with the level of global and regional brain atrophy. Objective: The present article aimed to identify structural changes related to socio-cognitive performance in a sample of patients with relapsing-remitting multiple sclerosis. Methods: 68 relapsing-remitting multiple sclerosis Chilean patients and 50 healthy control subjects underwent MRI scans and neuropsychological evaluation including social-cognition tasks. Total brain, white matter, and gray matter volumes were estimated. Also, voxel-based morphometry was applied to evaluate regional structural changes. Results: Patients exhibited lower scores in all neuropsychological tests. Social cognition exhibited a significant decrease in this group mostly related to the declining social perception. Normalized brain volume and white matter volume were significantly decreased when compared to healthy subjects. The regional brain atrophy analysis showed that changes in the insular cortex and medial frontal cortices are significantly related to the variability of social-cognitive performance among patients. Conclusions: In the present study, social cognition was only correlated with the deterioration of verbal fluency, despite the fact that previous studies have reported its link with memory and executive functions. The identification of specific structural correlates supports the comprehension of this phenomenon as an independent source of cognitive disability in these patients.
\end{abstract}

Keywords: Multiple Sclerosis; Social Cognition; Theory of Mind; Social Perception; Brain Atrophy.

\section{RESUMEN}

Antecedentes: La esclerosis múltiple presenta fenómenos neuropatológicos específicos que conducen a la atrofia cerebral global y regional. A nivel clínico, la enfermedad está relacionada con el deterioro funcional de los dominios cognitivos como la memoria de trabajo, la velocidad de procesamiento y la fluidez verbal. Sin embargo, el compromiso de las habilidades socio-cognitivas ha concentrado cierto interés en los últimos años debido a la evidencia disponible que sugiere el riesgo de desorganización en la vida social. Estudios recientes han utilizado la prueba MiniSEA para evaluar el compromiso de la cognición social y han encontrado relaciones relevantes con la memoria y funciones ejecutiva, así como con el nivel de atrofia cerebral global y regional. Objetivo: El presente artículo tiene como objetivo identificar cambios estructurales relacionados con el rendimiento sociocognitivo en una muestra de pacientes con esclerosis múltiple recurrenteremitente. Métodos: 68 pacientes Chilenos con esclerosis múltiple recurrente-remitente y 50 sujetos de control sanos se sometieron a resonancias magnéticas y evaluación neuropsicológica, incluidas las tareas de cognición social. Se estimaron los volúmenes cerebrales totales, de materia blanca y materia gris. Además, se aplicó la morfometría basada en vóxel para evaluar los cambios estructurales

\footnotetext{
${ }^{1}$ Universidad de Santiago de Chile, Escuela de Medicina, Santiago, Chile.

${ }^{2}$ Pontificia Universidad Católica de Chile, Interdisciplinary Center of Neurosciences, Santiago, Chile.

${ }^{3}$ Pontificia Universidad Católica de Chile, Biomedical Imaging Center, Santiago, Chile.

${ }^{4}$ Pontificia Universidad Católica de Chile, Neurology Department, School of Medicine, Santiago, Chile.

${ }^{5}$ Pontificia Universidad Católica de Chile, Radiology Department, School of Medicine, Santiago, Chile.

${ }^{6}$ Millenium Nucleus for Cardiovascular Magnetic Resonance, Santiago, Chile.

7Pontificia Universidad Católica de Chile, Interdisciplinary Center of Neurosciences, Santiago, Chile.

${ }^{8}$ Pontificia Universidad Católica de Chile, Psychiatry Department, School of Medicine, Santiago, Chile.

TPL (D) https://orcid.org/0000-0002-1566-5940; CM (D) https://orcid.org/0000-0003-3370-0233; MZ (D) https://orcid.org/0000-0002-4847-311X;

ELC (iD https://orcid.org/0000-0002-7330-5433;JPC (iD) https://orcid.org/0000-0002-7524-7273; MV (iD) https://orcid.org/0000-0001-7074-5903;

SU (D) https://orcid.org/0000-0002-4970-9710; NC (ID https://orcid.org/0000-0002-3060-656X; CC (D) https://orcid.org/0000-0002-9430-216X

Correspondence: Claudia Cárcamo Rodríguez; Email:ccarcamo@med.puc.cl.

Conflict of interest: There is no conflict of interest to declare.

Authors' contributions: TL, EC, CC: conceived of the presented idea; TL: wrote the manuscript with support from NK, CC; JPC, MV, SU: helped supervise the project; TL, MZ, CM carried out the experiments.

Received on April 15, 2020; Received in its final form on November 04, 2020; Accepted on November 22, 2020.
} 
regionales. Resultados: Los pacientes muestran puntuaciones más bajas en todas las pruebas neuropsicológicas. La cognición social exhibe una disminución significativa en este grupo principalmente relacionada con la disminución de la percepción social. El volumen normalizado del cerebro y el volumen de la materia blanca disminuyeron significativamente en comparación con los sujetos sanos. El análisis regional de atrofia cerebral mostró que los cambios en la corteza insular y la corteza frontal medial están significativamente relacionados con la variabilidad del rendimiento sociocognitivo entre los pacientes. Conclusiones: En el presente estudio, la cognición social sólo se correlacionó con el deterioro de la fluencia verbal, a pesar de que estudios previos han reportado su vinculación con la memoria y funciones ejecutivas. La identificación de correlatos estructurales específicos apoya la comprensión de este fenómeno como una fuente independiente de discapacidad cognitiva en estos pacientes.

Palabras clave: Esclerosis Múltiple; Cognición Social; Teoría de la Mente; Percepción Social; Atrofia Cerebral.

\section{INTRODUCTION}

Multiple sclerosis (MS) has become a significant source of disability and cognitive impairment in young patients ${ }^{1}$ attributed to a disconnection syndrome derived from white matter damage ${ }^{2}$.

The patients develop subclinical or measurable cognitive decline since the earliest stages of the disease, with significant changes in cortical recruitment related to cognitive tasks ${ }^{3}$. These phenomena can be understood as the use of cognitive reserve and the start of neural compensation ${ }^{4}$. Interestingly, the existence of mild involvement of socio-cognitive functions early in the MS onset ${ }^{5}$ has attracted less interest and could be related to similar mechanisms as those described previously.

Social cognition is defined as the integration of the processes that allow interaction among subjects. It relies on the exchange of social signals that enable us to obtain information about other persons and learn about the environment. Starting from a fundamental phenomenon of attribution of intention, social cognition allows the generation of a shared reality ${ }^{6}$. Some of its most studied domains are theory of mind, the ability to represent the psychological perspective of other subjects ${ }^{7}$, and social perception, the ability to perceive mental states of others based on behavioral signals. There are different approaches to the clinical evaluation of these cognitive domains, allowing to measure whether the subjects can perceive socially relevant information from their environment and to elaborate a coherent mental representation of the cognitive world of others ${ }^{8}$. In this article, the theory of mind can be measured by the faux-pas test (short stories in which intentions must be inferred) and social perception by a series of images in which the patient must identify the emotion that is expressed ( face emotion recognition test, as detailed in the methods section).

There is emerging evidence on the compromise of social cognition in MS and its relatively constant relationship with other cognitive domains ${ }^{9}$. However, the wide variability of the subjects studied in Latin America and the Caribbean has made it difficult to reach a pertinent neuropsychological approach to the local characteristics of the patients, at the same time that the peculiarities of social cognition in this group of patients have not been systematically studied ${ }^{10}$. Recently, a significant relationship with impaired memory and executive functions has been shown, as well as with different measures of global brain atrophy and regional changes in associative visual and executive cortical areas in progressive forms of the disease ${ }^{11}$.

The present study aimed to identify changes in the sociocognitive performance and related structural and clinical findings in a sample of Chilean patients with relapsing-remitting MS.

\section{METHODS}

The present investigation was approved by the ethics committee of the medical school of the Pontifical Catholic University of Chile. All subjects gave their informed consent.

\section{Recruitment}

Patients with relapsing-remitting MS under clinical follow-up at a single university center in Chile were invited to participate in a neuropsychological evaluation concomitant with their routine scheduled radiological control. Subjects with Mini Mental state examination (MMSE) score lower than 24 points and significant cognitive impairment in previous screenings were excluded as required by local regulatory law for clinical research. Only patients without acute symptoms or active clinical progression were included.

Healthy volunteers recruited through advertisements in university and healthcare settings, with matched education and age, were included to undergo the same neuropsychological examination, and structural/functional images were acquired using the same protocol.

Information about age, achieved educational level, and employment status was registered for both groups. The patients' expanded disability status scale (EDSS) score and disease duration were registered.

We included 68 patients and 50 healthy control subjects who underwent a full neuropsychological evaluation and 
magnetic resonance imaging. Twenty-six (52\%) participants in the healthy control group and $48(70.6 \%)$ in the patients group were women ( $p=0.039$, chi-square test).

The mean age was $37.43 \pm 11.2$ years in the patients and $37.97 \pm 10.76$ years in the control group ( $p$-value $=0.765$ ) The mean disease duration was $5.052 \pm 3.649$ years, and the median EDSS was 1 (range 1-4.5). Most patients (94.3\%) had a university or technical career compared to $98 \%$ in the control group ( $p$-value $=0.098$ ). Employability level was $91.5 \%$ in the patients and $94 \%$ in the control subjects, $(p$-value $=0.731)$.

\section{Neuropsychological evaluation}

Cognitive evaluation was based on the widely reported approach for MS patients ${ }^{12}$. Processing Speed (Symbol Digit Modality Test - SDMT) ${ }^{13}$, Verbal and Visual Episodic Memory, California Verbal Learning Test (CVLT), the Brief Visuospatial Memory Test-Revised (BVMT-R) ${ }^{14}$, Working Memory, Paced Auditory Serial Addition Test (PASAT) ${ }^{15}$, Inhibitory control (Stroop test, Spanish version) $)^{16}$, and cognitive shifts with categorical flexibility and lexical fluency, and control of interference (FAS test) ${ }^{17}$ were measured. All the cognitive tasks were performed in Spanish by a single trained evaluator as previously detailed ${ }^{11}$. Performance in each of these cognitive tasks was expressed as a z-score (the z-score was calculated using the means and standard deviations derived from the local validation of the test).

Depression, fatigue, and mental status were evaluated by applying the Beck Depression Inventory II (BDI-II) ${ }^{18}$, Fatigue Severity Scale $(\mathrm{FSS})^{19}$, and Mini-Mental Status Examination (MMSE), respectively. Even considering the well-known limitations of MMSE, it was applied to all subjects according to the local regulatory law for clinical research. Social cognition was evaluated using the Mini-Social Cognition and Emotional Assessment (MiniSEA) ${ }^{20}$, a 30 min composite battery, which is the reduced version of the Social Emotional Assessment test $^{21}$. The MiniSEA consists of two different items including a shortened version of the Faux-Pas (FP) and the Face Emotion Recognition to evaluate the theory of mind and social perception, respectively. Facial emotion recognition is considered a relevant and useful approach to evaluate the social perception domain ${ }^{22}$.

The theory of mind section includes ten short stories in which a character inadvertently hurts or offends another. Then, the subject needs to infer the other's mental state by making attributions to their knowledge, beliefs, and emotions. Half of the vignettes are control stories, and the other half includes a principal character who inadvertently offends another. The subject is expected to recognize the situations in which an FP is committed, why the leading subject did it (cognitive theory of mind), and how the victim must have felt (affective theory of mind). The Social Perception item consists of 35 pictures for face affect recognition of basic emotions among a list presented at the bottom of the screen including happiness, sadness, anger, surprise, fear, disgust, and neutrality. A global MiniSEA score and individual performances on social perception and theory of mind task were obtained separately. Given the absence of a locally validated version of MiniSEA, the results are expressed as absolute scores. Social perception and Theory of Mind scores were calculated by expressing the total punctuation as a fraction of 15 points each one. MiniSEA total score was obtained as the sum of both subdomains scores.

The neurocognitive assessment was performed within ten days after the MRI acquisition. The entire neuropsychological examination of each patient took approximately 40 minutes.

\section{Magnetic resonance imaging parameters}

Images were acquired by a Philips Ingenia $3 \mathrm{~T}$ MRI scanner. T1 weighted 3D images (TR 7.8 ms, TE 3.6 ms, FOV 240 x 240 x 164, flip angle $8^{\circ}$, SENSE factor 2.5, acquisition time 4 min 8 s) and FLAIR (TR $4800 \mathrm{~ms}$, TE $290 \mathrm{~ms}$, FOV 240 x $240 \mathrm{x}$ 164 , acquisition time 4 min $33 \mathrm{~s}$ ) sequences were acquired for the segmentation of brain lesions as detailed below.

\section{Structural study}

Structural Image Evaluation using Normalization of Atrophy (SIENAX ${ }^{23}$, part of FSL, Fmrib, Oxford, UK, available at http://www.fmrib.ox.ac.uk/) was used to estimate brain tissue volume, normalized for subject head size. SIENAX starts by extracting brain and skull images from the single wholehead input data. The brain image is then affine-registered to MNI152 space (using the skull image to determine the registration scaling); this is primarily done to obtain the volumetric scaling factor, to be used as a normalization for head size. Next, tissue-type segmentation with partial volume estimation is carried out to calculate the total volume of brain tissue (including separate estimates of volumes of grey matter, white matter, peripheral grey matter, and ventricular CSF).

\section{Voxel-based morphometry (VBM)}

Lesions were segmented by the lesion growth algorithm ${ }^{24}$ as implemented in the LST toolbox version 1.2.3 (http://www. statisticalmodelling.de/lst.html) for SPM. The algorithm first segments the T1 weighted images into the cerebrospinal fluid, grey matter, and white matter. This information is then combined with the co-registered FLAIR intensities to calculate lesion belief maps. By thresholding these maps with a prechosen initial threshold $(\mathrm{k})$, an initial binary lesion map is obtained which is subsequently grown along voxels that appear hyperintense in the FLAIR.

The outcome, a lesion probability map, in alignment with a $\mathrm{T} 1$ weighted $3 \mathrm{D}$ image, creates a filled image in native space. Then, volumes based on a voxel-wise comparison of grey and white matter volumes were applied to T1 weighted filled images by using SPM8 (statistical parametric mapping 8; functional imaging laboratory, Wellcome Department of 
Imaging Neuroscience, Institute of Neurology, London, UK; http://www.fil.ion.ucl.ac.uk/spm). It was run on Matlab 2015b (Mathworks, Natick, MA, USA). T1 weighted filled images were segmented, replaced to a DARTEL template, and then normalized to MNI space using VBM8 preprocessing in SPM ${ }^{25}$. A two-sample t-test was selected as a factorial design to perform a regional comparison between control subjects and patients. Multiple regression was chosen as the factorial design for MiniSEA, social perception, and theory of mind scores. Interaction analysis was performed to look for differences in the association of regional brain volume and cognitive performance between groups. Significance was assessed using a family-wise error (FWE) corrected for $\mathrm{p}$-value $<0.05$ and cluster size $>20$ voxels. The cluster size was selected considering the main size of the regions included in the HarvardOxford Atlas to avoid the over-representation of small clusters mostly related to noise ${ }^{26}$.

\section{Statistical analysis}

Statistics were performed using Minitab 17 Statistical Software (2010) Computer software, State College, PA, Minitab, Inc. (http://www.minitab.com). Non-parametric tests were selected since that normality of the data was discarded using the Kolmogorov-Smirnov test. Correlation between continuous variables (scores in neuropsychological examinations) was assessed using the Spearman correlation. Differences between groups (age, fatigue, depression, MMSE, and neuropsychological scores) were assessed using the Mann-Withney U test. The interaction of potential confounders, as depression and fatigue scores, with traditional and socio-cognitive domains and the effect of differences in gender composition in the relationship between the domains of social cognition and traditional cognitive domains were assessed by Analysis of Covariance (ANCOVA). The result was considered significant with a p-value $<0.05$.

The primary outcomes analyzed through this research were social cognition scores and regional volume as assessed by VBM. Being part of each group (healthy control or patients) was considered as a modifying factor of the effect in the association between clinical findings and MRI data.

\section{RESULTS}

No significant difference in mental status (MMSE) was found in comparison with healthy subjects, while significantly higher scores in fatigue and depression questionnaires were found in the patient group (Table 1).

\section{Neuropsychological assessment}

Significantly lower scores were obtained for the patient group in processing speed (SDMT, $\mathrm{p}=0.005$ ), verbal fluency (FAS, $p=0.001$ ), and verbal (CVLT, $P=0.029$ ) and visual memories (BVMT-R, $\mathrm{p}<0.001$ ) compared to healthy controls (Table 2).

As shown in Table 3, patients exhibited a lower score than the control subjects in the MiniSEA (25.26 vs. 26.106, p $=0.046$ ) and FER test (11.83 vs. 12.82, $\mathrm{p}=0.015$ ). The faux-pas score was lower in the patient group, but without statistical significance (13.725 vs. 14.624, $\mathrm{p}=0.153$ ).

No significant correlation was found between the performance in neurocognitive tasks and socio-cognition performance, except by verbal fluency and global MiniSEA score in the patient's group (rho $=0.365, \mathrm{p}=0.003$ ).

A significant correlation was not found for the patient group between fatigue and the MiniSEA score (rho $=0.123$, 95\%CI (-0.143; 0.373), $\mathrm{p}=0.361)$, FER test $(\mathrm{rho}=-0.075,95 \% \mathrm{CI}$ $(-0.329 ; 0.190), \mathrm{p}=0.579)$, or faux-pas test ( $\mathrm{rho}=0.147,95 \% \mathrm{CI}$ $(-0.120 ; 0.394, p=0.276)$. Also, no significant correlation was found in the control subjects with the MiniSEA score (rho = 0.161, 95\%CI (-0.124; 0.422, $\mathrm{p}=0.263)$, FER test ( $\mathrm{rho}=0.140$, 95\%CI $(-0.145 ; 0.404, \mathrm{p}=0.332)$, or Faux-pas test $($ rho $=0.172$, 95\%CI $(-0.114 ; 0.431, \mathrm{p}=0.233)$

On the other hand, the patients showed a significant correlation between the depression scale score and the MiniSEA score $($ rho $=0.299,95 \% \mathrm{CI}(0.036 ; 0.524, \mathrm{p}=0.024)$ and faux-pas test (rho $=0.345,95 \% \mathrm{CI}(0.086 ; 0.561), \mathrm{p}=0.008)$, but not significant with the FER test score (rho $=0.011,95 \%$ CI $(-0.250$; 0.271, $\mathrm{p}=0.933)$. A significant correlation was not found in the control subjects for the MiniSEA score (rho $=0.210,95 \% \mathrm{CI}$ $(-0.076 ; 0.464, \mathrm{p}=0.144)$, FER test $($ rho $=0.246$, 95\% CI $(-0.039$;

Table 1. Mental health parameters of control subjects $(n=50)$ and patients $(n=68)$. Depression (Beck), Fatigue (Krupp), and mental status are shown for both groups and disability level and disease evolution time are shown for the patient group.

\begin{tabular}{lccc} 
& Healthy Control & Patients & p-value \\
\hline BDI-II (Mean \pm SD) & $15.50 \pm 7.4$ & $21 \pm 15.38$ & $0.001 *$ \\
\hline FSS (Mean \pm SD) & $1.951 \pm 0.823$ & $2.915 \pm 1.708$ & $0.009 *$ \\
MMSE (Mean \pm SD) & $29.58 \pm 0.6$ & $29.64 \pm 0.7$ & 0.374 \\
EDSS ( Median [Min., Max., IQR]) & - & $1[0.5 .2]$ & $5.052 \pm 3.649$ \\
\hline Disease duration time in years (Mean \pm SD) & - & & \\
\hline
\end{tabular}

${ }^{*} p<0.05$, statistically significant results.

BDI-II: Beck Depression Inventory II; FSS: Fatigue Severity Scale; MMSE: Mini Mental Status Scale Examination; EDSS: Expanded Disability Status Scale, SD: standard deviation. 
0.494, $\mathrm{p}=0.085)$ or faux-pas test $(\mathrm{rho}=0.095,95 \% \mathrm{CI}(-0.189$; $0.364, \mathrm{p}=0.512$ ).

There was no significant effect of the group on social cognition performance after controlling per fatigue level (MiniSEA $\mathrm{F}=0.52, \mathrm{p}=0.452$; face emotion recognition $\mathrm{F}=$ $0.01, p=0.903$; faux-pas $F=0.57, p=0.452$ ) or depressive status (MiniSEA F $=0.81, \mathrm{p}=0.371$; face emotion recognition $\mathrm{F}=0.52$, $\mathrm{p}=0.472$; faux-pas $\mathrm{F}=0.03, \mathrm{p}=0.853$ ).

Given the absence of a perfect match in gender composition between the healthy control and patient groups, we also studied the effect of this variable in the observed differences in social cognition. Nevertheless, no significant influence of gender was observed for MiniSEA ( $\mathrm{F}=1.83, \mathrm{p}=0.179$ ), Social Perception $(\mathrm{F}=0.01, \mathrm{p}=0.943)$, or Theory of Mind $(\mathrm{F}=3.10$, $\mathrm{p}=0.081$ ) scores.

Additionally, when correcting for the effect of differences in gender composition in the relationship between the domains of social cognition and traditional cognitive domains, the analysis of covariance did not show a significant effect of the other cognitive tests on the global score of MiniSEA or the domain of social perception. Only a little higher variability in the theory of mind score was observed due to the effect of performance in the visual memory test $(\mathrm{F}=5.23, \mathrm{p}=0.025)$.

\section{Structural analysis}

Patients exhibited significantly lower whole brain and white matter volumes compared to healthy controls (Table 4). No significant correlation between those global or segmentary volumes and sociocognition performance was found.

When looking for differences in regional atrophy between groups, we found significant clusters of voxels in both hemispheres compromising insula, caudate, cingulate gyrus, and medial frontal gyrus showing decreased values in patients compared to control subjects (Figure 1).

When the correlation between Regional Volume and Social Cognition Performance was analyzed, specific areas such as the insula, medial frontal cortex, and cingulate cortex were significantly correlated to the cognitive processes of social perception and theory of mind in both patient and control groups (Figure 2).

The interaction analysis showed that the left insula and both medial frontal regions had significantly different levels of association with the theory of mind and social perception scores (Figure 3). Table 5 details the coordinates, laterality, and size of the identified regions.

\section{DISCUSSION}

The present study recruited a considerably large sample of patients with recurrent remitting MS and a control group matched by age and educational level, with the aim of studying the deteriorations in the treatment of social cognition and the brain structure changes associated with this phenomenon.

Table 2. Differences in cognitive performance considering conventional domains. Healthy control group $(n=50)$. Multiple sclerosis patients $(n=68)$

\begin{tabular}{llccc}
\hline Test & Group & Median & SD & p-value \\
\hline SDMT & Control & 0.403 & 0.882 & $0.005^{\star *}$ \\
& Patients & -0.03 & 1.141 & \\
\hline PASAT & Control & -0.123 & 0.97 & 0.094 \\
& Patients & -0.52 & 1.381 & \\
\hline CVLT* & Control & -0.569 & 1.455 & $0.029 * *$ \\
& Patients & -1.298 & 2.027 & \\
\hline BVMT-R* & Control & 0.611 & 0.911 & $<0.001 * \star$ \\
& Patients & -0.166 & 1.38 & \\
\hline FAS & Control & 1.348 & 1.49 & $0.001 * *$ \\
& Patients & 0.335 & 1.163 & \\
\hline Stroop & Control & -0.69 & 7.36 & 0.773 \\
\hline
\end{tabular}

$\star$ Delayed free recall scores; $* \star p<0.05$, statistically significant results; SD:standard deviation; SDMT: Symbols and Digit Modality Test; PASAT: Paced Auditory Serial Addition test; CVLT: California Visual and Verbal Learning test; BVMT: Brief Visuospatial Memory test-revised; FAS: Fluency test.

Table 3. Social cognition results: global MiniSEA scores and subdomains. Comparison between groups is shown. Healthy control group ( $n=50)$, multiple sclerosis patients $(n=68)$.

\begin{tabular}{lcccc}
\hline & Group & Median & IQR & p-value \\
\hline MiniSEA & Control & 26.106 & 3.96 & \\
& Patients & 25.26 & 3.033 & $0.046^{*}$ \\
Facial emotion & Control & 12.82 & 2.09 & \\
recognition & Patients & 11.83 & 1.738 & $0.015^{\star}$ \\
& Control & 14.625 & 2.25 & \\
Faux-pastest & Patients & 13.725 & 2.7 & 0.153 \\
\hline
\end{tabular}

${ }^{*} \mathrm{p}<0.05$, statistically significant results.

MiniSEA: Mini-Social Cognition and Emotional Assessment.

Table 4. Brain volume comparison. Median of all volumes measured by the SIENAX algorithm are higher in the control group (Control group, $n=50$; Patients $n=68$ ).

\begin{tabular}{lccc}
\hline & $\begin{array}{c}\text { Healthy control } \\
\text { (Median) }\end{array}$ & $\begin{array}{c}\text { Patients } \\
\text { (Median) }\end{array}$ & p-value \\
\hline $\begin{array}{l}\text { Normalized } \\
\text { brain volume }\end{array}$ & 1556749 & 1525070 & $0.001^{*}$ \\
$\begin{array}{l}\text { Grey matter } \\
\text { volume }\end{array}$ & 781920 & 773392 & 0.162 \\
$\begin{array}{l}\text { White matter } \\
\text { volume }\end{array}$ & 777425 & 752897 & $<0.001^{\star}$ \\
\hline
\end{tabular}

${ }^{*} p<0.05$, statistically significant results. 


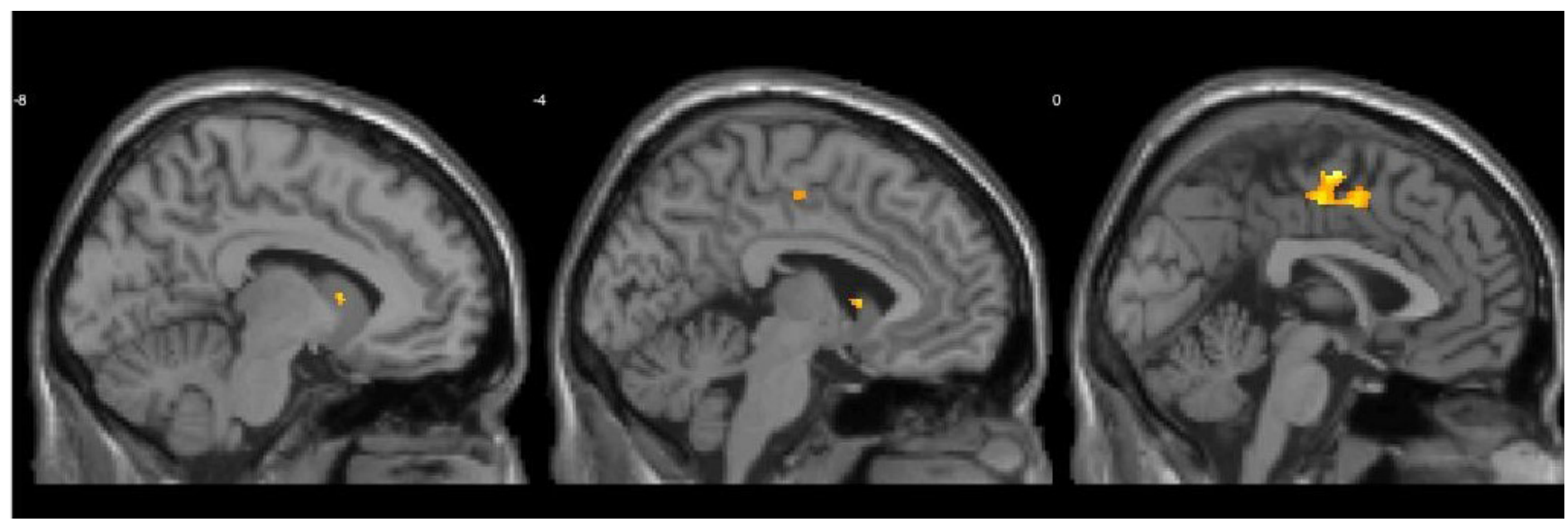

Figure 1. Voxel Based Morphometry. Selected sagittal images show voxels with significant differences between healthy control group $(n=50)$ and multiple sclerosis patients $(n=68)$. Brain atrophy observed in multiple sclerosis is not a homogenously distributed phenomenon; specific brain regions concentrate more atrophy. Insula, caudate, cingulate gyrus, and medial frontal gyrus are among the compromised regions also frequently involved in social cognition processes (comparison of control subjects versus patients). Only significant clusters are shown ( $p<0.05)$. Warmer colors represent higher T-values.
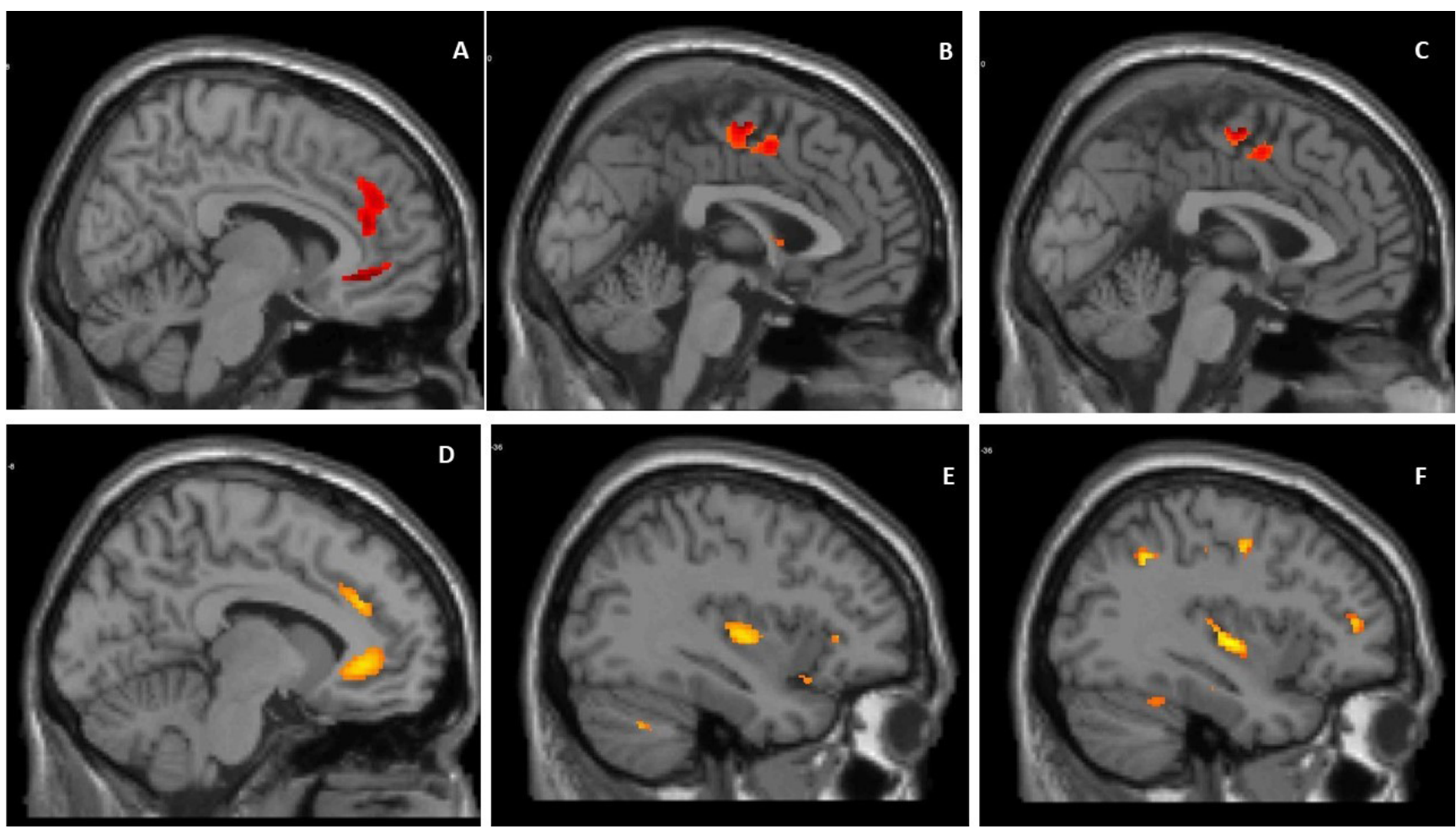

Figure 2. Brain areas showing significant association between regional volume and aocial cognition performance. Selected sagittal images showing in A, MiniSEA, B, social perception, and C, theory of mind in the patient group ( $n=68) ; D, M i n i S E A, E$, social perception, and F, theory of mind in healthy control subjects $(n=50)$. Only significant clusters are shown $(p<0.05)$. Warmer colors represent higher T-values.

The distribution of the findings in the neuropsychological study requires some attention. The compromise of processing speed, verbal fluency, and verbal and visual memories are compatible with the findings reported in the literature ${ }^{27}$. The relative conservation of performance in tests of working memory and cognitive interference may be related to compensatory changes in brain connectivity, the study of which will require a functional approach. Despite some variations, our neuropsychological findings were in a feasible range of the patients with $\mathrm{MS}^{28}$. Possibly, the relative preservation of several explored neurocognitive domains may be related with some characteristics of the sample, as the disease duration and wide use of therapies directed to modify the course of the disease were present in our center.

Despite the relative independence of social cognition from performance on other cognitive tests, there was a 

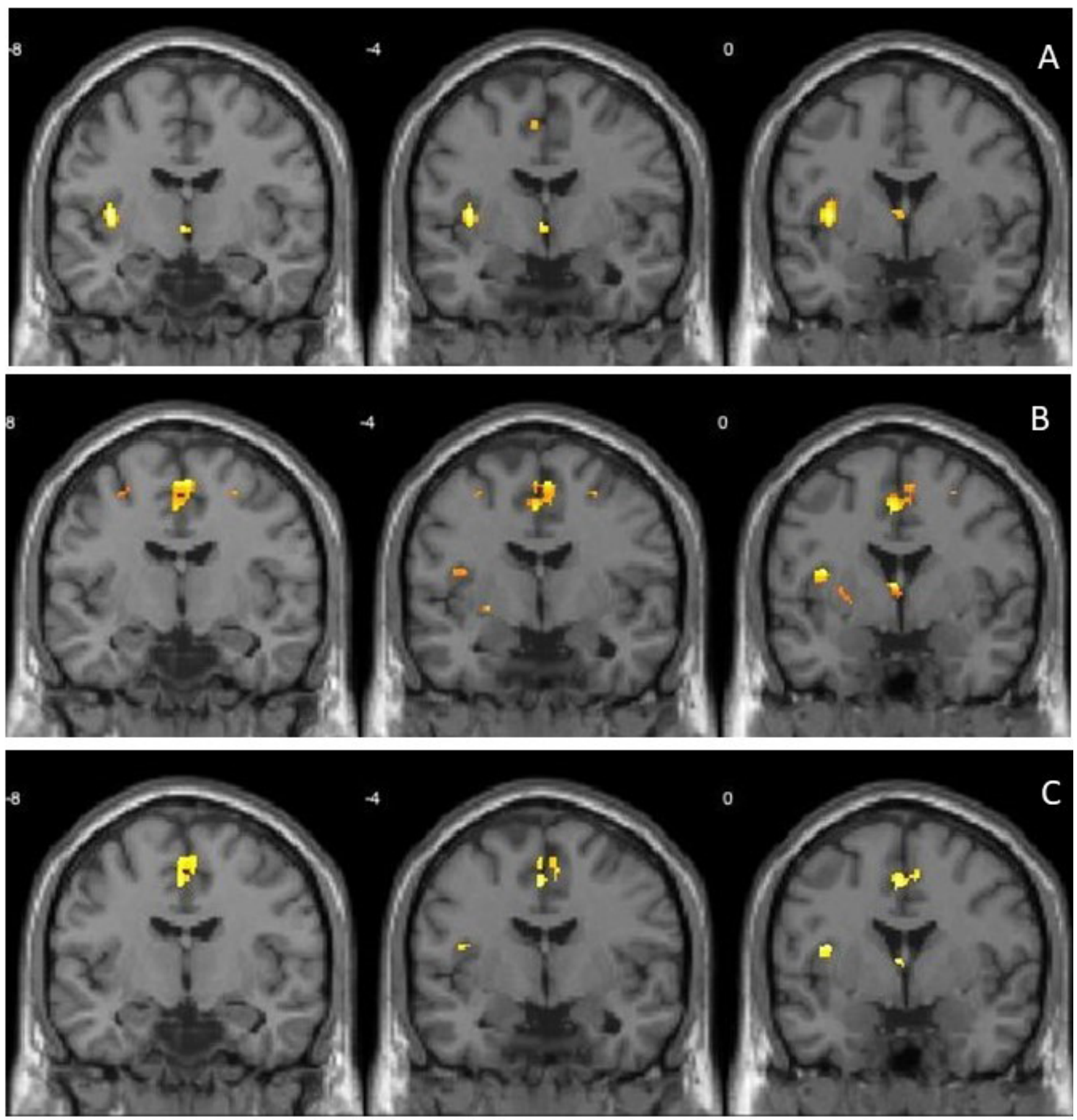

VBM:Voxel-based morphometry; MS: multiple sclerosis; MiniSEA: Mini-Social Cognition and Emotional Assessment.

Figure 3. VBM interaction analysis. Clusters whose levels of association with social cognition performance are significantly different in healthy control $(n=50)$ versus MS patients ( $n=68$, information displayed in selected coronal views). A: MiniSEA; B: social perception; C: theory of mind. Insula and medial frontal regions are among the areas of neuropsychological relevance whose volumetry is associated with measures of social cognition. Only significant clusters are shown ( $p<0.05)$. Warmer colors represent higher T-values.

significant correlation with the verbal fluency test in the group of patients. There is evidence that sociocognitive functioning and measures of rapid information flow such as verbal fluency are related. The focus of this relationship would be found in the neurodynamics of prefrontal regions ${ }^{29}$. At the same time, it is important to recognize that the findings on both the pattern of socio-cognitive deterioration in MS and its correlation with the structural study do not exactly coincide with what was previously reported, even using the same test battery. A recent study reports a significant relationship of the domains of social cognition with performance in memory and executive functions tests, as well as an association with global brain atrophy and areas of visual association. This differs significantly from our findings, even though 
Table 5. Voxel Based Morphometry comparison of association between social cognition performance and regional brain volume in control ( $n=50)$ versus patients $(n=68)$ (interaction analysis). The left insula and medial frontal region (bilateral) showed significantly different levels of association with the theory of mind and social perception in healthy control subjects and RR-MS patients. Interestingly, those regions exhibit a well-documented influence in socio-cognitive functions.

\begin{tabular}{|c|c|c|c|c|c|c|c|}
\hline \multicolumn{8}{|c|}{ Peak MNI Coordinates } \\
\hline Task & Hemisphere & Brain region & Cluster size & $x$ & $\mathrm{Y}$ & Z & Peak intensity (t value) \\
\hline \multirow[t]{9}{*}{ MiniSEA } & L & Insula & 556 & -37.5 & -7.5 & 6 & 3.4151 \\
\hline & $\mathrm{R}$ & Putamen & 52 & 25.5 & 7.5 & 6 & 2.5131 \\
\hline & L & Putamen & 55 & -25.5 & 6 & 6 & 2.282 \\
\hline & $\mathrm{R}$ & Thalamus & 22 & 3 & -24 & 9 & 2.6437 \\
\hline & $L$ & Precuneus & 200 & -6 & -66 & 28.5 & 2.3188 \\
\hline & $\mathrm{R}$ & Precuneus & 22 & 15 & -55.5 & 51 & -2.6159 \\
\hline & $\mathrm{R}$ & Middle Frontal Gyrus & 54 & 28.5 & -6 & 52.5 & -2.1859 \\
\hline & $\mathrm{R}$ & Superior Frontal Gyrus & 42 & 22.5 & 10.5 & 52.5 & -2.2862 \\
\hline & L & Medial Frontal Gyrus & 39 & 0 & -9 & 58.5 & -2.8403 \\
\hline
\end{tabular}

\section{Social perception}

\begin{tabular}{|c|c|c|c|c|c|c|}
\hline & Insula & 169 & -36 & -18 & 3 & -2.8699 \\
\hline & Insula & 393 & -36 & 9 & 15 & 4.2085 \\
\hline & Caudate & 401 & -7.5 & 10.5 & 7.5 & 4.2433 \\
\hline & Thalamus & 22 & 3 & -25.5 & 7.5 & 2.3914 \\
\hline & Medial Frontal Gyrus & 167 & -12 & 16.5 & 48 & -3.3116 \\
\hline & Medial Frontal Gyrus & 946 & 3 & -15 & 57 & 3.8668 \\
\hline & Parietal Lobe & 66 & -31.5 & -52.5 & -40.5 & -2.4902 \\
\hline & Medial Frontal Gyrus & 34 & 12 & 34.5 & 39 & -4.3898 \\
\hline & Middle Frontal Gyrus & 52 & -28.5 & 13.5 & 43.5 & -4.7525 \\
\hline & Parietal Lobe & 25 & -37.5 & -30 & 48 & 2.9788 \\
\hline & Middle Frontal Gyrus & 116 & 27 & 19.5 & 48 & 3.0708 \\
\hline & Middle Frontal Gyrus & 20 & -30 & -4.5 & 54 & 2.3153 \\
\hline \multicolumn{7}{|l|}{ Theory of mind } \\
\hline & Insula & 604 & -34 & 9 & 14 & 4.4925 \\
\hline & Insula & 169 & -37.5 & -18 & 1.5 & -2.3379 \\
\hline & Caudate & 508 & -7.5 & 10.5 & 7.5 & 5.5474 \\
\hline & Thalamus & 21 & 3 & -24 & 9 & 2.8925 \\
\hline & Posterior Cingulate & 50 & -3 & -61.5 & 22.5 & 2.0879 \\
\hline & Medial Frontal Gyrus & 204 & -12 & 34.5 & 40.5 & -3.91898 \\
\hline & Parietal Lobe & 50 & 1.5 & -69 & 37.5 & 2.9298 \\
\hline F & Cingualte Gyrus & 1326 & -1.5 & -1.5 & 46.5 & 3.7867 \\
\hline$L$ & Parietal Lobe & 120 & -36 & -46.5 & 40.5 & -2.427 \\
\hline & Medial Frontal Gyrus & 36 & 12 & 34.5 & 40.5 & -3.9899 \\
\hline$L$ & Middle Frontal Gyrus & 60 & -28.5 & 13.5 & 43.5 & -4.1395 \\
\hline & Middle Frontal Gyrus & 54 & 27 & 19.5 & 48 & 2.8369 \\
\hline & Parietal Lobe & 27 & 15 & -55.5 & 51 & -2.9776 \\
\hline$L$ & Medial Frontal Gyrus & 26 & -10.5 & 6 & 55.5 & -3.2675 \\
\hline $\mathrm{r}$ & Middle Frontal Gyrus & 30 & 28.5 & -4.5 & 54 & 3.1619 \\
\hline
\end{tabular}

MiniSEA: Mini-Social Cognition and Emotional Assessment; L: left, R: right. 
the sample was also Latin American patients (specifically Chilean). This is probably related to different clinical expressions in RR-MS and primary progressive patients. The relative importance of each sub-domain and its structural correlate vary significantly ${ }^{11}$.

The above described pattern may have a functional correlate with the findings in the exploration of social cognition. Since this domain showed a compromise based fundamentally on the change in performance in the facial expression recognition test, there is evidence of the relationship of this process with the information processing speed. The relative conservation of the Theory of Mind domain is probably related to the greater complexity of this process and the conservation of the processes of cognitive interference and working memory involved in the performance of these tests. On the other hand, the significant correlation between verbal fluency and the MiniSEA score has a history in the multiple sclerosis literature ${ }^{30}$. Although it would be beyond the sensitivity of our statistical method, we speculate that this process would be mediated by the effect on social perception, since that the FAS test is considered an adequate measure of the integrity of the processes of information flow, flexibility, and control of cognitive interference ${ }^{17}$.

On the other hand, the level of selected depressive symptoms was shown to significantly impact performance in the social cognition test, especially the social perception subdomain. Although some background has indicated the independence of mood and social cognition performance in $\mathrm{MS}^{31,32}$, the interference of depression in social cognition has been reported in other clinical settings ${ }^{31}$.

Although in this sample of patients it was possible to rule out the influence of gender on the differences observed in the domain of social cognition, it is important to recognize that gender has been classically associated with socio-cognitive variability. However, many of the differences in this area refer to developmental aspects ${ }^{33,34}$. A future study with a design that could exclude this factor would provide more insight.

This article contributes to clarifying one of the several expressions of social cognition deterioration in MS. Specifically, robust corroboration of the decline in facial expression recognition and its neural correlates has been accomplished. Additionally, our results have the interesting feature of exploring this cognitive process in a considerable number of Latin American patients.

\section{ACKOWLEDGEMENTS}

T. Labbe thanks CONICYT (Comisión Nacional de Ciencia y Tecnología) for the doctoral scholarship (21160298) received during the development of this paper. The authors thank CONICYT-PIA, CONICYT, Project number ACT1416 for funding Support. SU thanks funding from the Millennium Science Initiative of the Ministry of Economy, Development and Tourism, grant Nucleus for Cardiovascular Magnetic Resonance; CONICYT, FONDECYT Regular Project Number 1181057.

\section{REFERENCES}

1. Eskandarieh S, Heydarpour P, Minagar A, Pourmand S, Sahraian MA. Multiple sclerosis epidemiology in East Asia, South East Asia and South Asia: a systematic review. Neuroepidemiology. 2016;46(3):20921. https://doi.org/10.1159/000444019

2. Zhou F, Zhuang Y, Gong H, Wang B, Wang X, Chen Q, et al. Altered inter-subregion connectivity of the default mode network in relapsing remitting multiple sclerosis: a functional and structural connectivity study. PLoS One. 2014 Jul 7;9(7):e101198.

3. Audoin B, Duong MVA, Ranjeva J-P, Ibarrola D, Malikova I, ConfortGouny S, et al. Magnetic resonance study of the influence of tissue damage and cortical reorganization on PASAT performance at the earliest stage of multiple sclerosis. Hum Brain Mapp. 2005 Mar;24(3):216-28. https://doi.org/10.1002/hbm.20083

4. Stern Y, Habeck C, Moeller J, Scarmeas N, Anderson KE, Hilton HJ, et al. Brain networks associated with cognitive reserve in healthy young and old adults. Cereb Cortex. 2005 Apr;15(4):394-402. https://doi. org/10.1093/cercor/bhh142

5. Jehna M, Neuper C, Petrovic K, Wallner-Blazek M, Schmidt R, Fuchs $S$, et al. An exploratory study on emotion recognition in patients with a clinically isolated syndrome and multiple sclerosis. Clin Neurol Neurosurg. 2010 Jul;112(6):482-4. https://doi.org/10.1016/j. clineuro.2010.03.020

6. Frith CD. Social cognition. Philos Trans R Soc Lond B Biol Sci. 2008 Jun 12;363(1499):2033-9. https://doi.org/10.1098/rstb.2008.0005
7. Baron-Cohen S. Without a theory of mind one cannot participate in a conversation. Cognition. 1988 Jun;29(1):83-4. https://doi. org/10.1016/0010-0277(88)90011-X

8. Labbé T, Ciampi E, Rodríguez CC. Social cognition: concepts, neural basis and its role in multiple sclerosis. Neurol Clin Neurosci. 2017 Oct 16;6:3-8. https://doi.org/10.1111/ncn3.12164

9. Bora E, Özakbaș S, Velakoulis D, Walterfang M. Social cognition in Multiple Sclerosis: a meta-analysis. Neuropsychol Rev. 2016 Jun;26(2):160-72. https://doi.org/10.1007/s11065-016-9320-6

10. Ferreira MLB. Cognitive deficits in multiple sclerosis: a systematic review. Arq Neuropsiquiatr. 2010 Aug;68(4):632-41. https://doi. org/10.1590/S0004-282X2010000400029

11. Ciampi E, Uribe-San-Martin R, Vásquez M, Ruiz-Tagle A, Labbe T, Cruz JP, et al. Relationship between social cognition and traditional cognitive impairment in Progressive Multiple Sclerosis and possible implicated neuroanatomical regions. Mult Scler Relat Disord. 2018 Feb;20:122-8. https://doi.org/10.1016/j.msard.2018.01.013

12. Benedict RHB, Smerbeck A, Parikh R, Rodgers J, Cadavid D, Erlanger D. Reliability and equivalence of alternate forms for the symbol digit modalities test: implications for multiple sclerosis clinical trials. Mult Scler. 2012 Sep;18(9)1320-5. https://doi. org/10.1177/1352458511435717

13. Smith A. SDMT: test de símbolos y dígitos: manual. Madrid:TEA Ediciones; 2002.40p. 
14. Benedict RHB. Brief visuospatial memory test revised professional manual. Odessa (FL): Psychological Assessment Resources, Inc; 1997.

15. Gronwall DM. Paced auditory serial-addition task: a measure of recovery from concussion. Percept Mot Skills. 1977 Apr;44(2):367-73. https://doi.org/10.2466/pms.1977.44.2.367

16. Golden C, Freshwater S, Golden Z. Stroop color and word test. APA PsycTests. 2002. https://doi.org/10.1037/t06065-000

17. Delis DC, Kaplan E, Kramer JH. Delis-Kaplan executive function system. Washington, D.C:American Psychological Association; 2001. https://doi.org/10.1037/t15082-000

18. Araneda RM, Solar FC, González PR, Peralta MV. Propiedades psicométricas del inventario de depresión de Beck-ll en adolescentes chilenos. Ter Psicol. 2008 Jul;26(1):59-69. https://doi.org/10.4067/ S0718-48082008000100005

19. Krupp LB, Coyle PK, Doscher C, Miller A, Cross AH, Jandorf L, et al. Fatigue therapy in multiple sclerosis: results of a double-blind, randomized, parallel trial of amantadine, pemoline, and placebo. Neurology. 1995 Nov 1;45(11):1956-61. https://doi.org/10.1212/ WNL.45.11.1956

20. Bertoux M, Volle E, de Souza LC, Funkiewiez A, Dubois B, Habert MO. Neural correlates of the mini-SEA (Social cognition and Emotional Assessment) in behavioral variant frontotemporal dementia. Brain Imaging Behav. 2014 Mar;8(1):1-6. https://doi.org/10.1007/s11682013-9261-0

21. Funkiewiez A, Bertoux M, Cruz de Souza L, Lévy R, Dubois B. The SEA (Social cognition and Emotional Assessment): a clinical neuropsychological tool for early diagnosis of frontal variant of frontotemporal lobar degeneration. Neuropsychology. 2012 Jan;26(1):81-90. https://doi.org/10.1037/a0025318

22. Jansen M, Overgaauw S, De Bruijn ERA. Social cognition and obsessive-compulsive disorder: a review of subdomains of social functioning. Front Psychiatry. 2020 Mar 13;11:118. https://doi. org/10.3389/fpsyt.2020.00118

23. Smith SM, Zhang Y, Jenkinson M, Chen J, Matthews PM, Frederico $A$, et al. Accurate, robust, and automated longitudinal and crosssectional brain change analysis. Neuroimage. 2002 Sep;17(1):479-89. https://doi.org/10.1006/nimg.2002.1040

24. Schmidt P, Gaser C, Arsic M, Buck D, Förschler A, Berthele A, et al. An automated tool for detection of FLAIR-hyperintense white-matter lesions in Multiple Sclerosis. Neuroimage. 2012 Feb 15;59(4):377483. https://doi.org/10.1016/j.neuroimage.2011.11.032
25. Ashburner J. A fast diffeomorphic image registration algorithm. Neuroimage. 2007 Oct 15;38(1):95-113. https://doi.org/10.1016/j. neuroimage.2007.07.007

26. Woo C-W, Krishnan A, Wager TD. Cluster-extent based thresholding in fMRI analyses: pitfalls and recommendations. Neuroimage. 2014 May 1;91:412-9. https://doi.org/10.1016/j.neuroimage.2013.12.058

27. Grzegorski T, Losy J. Cognitive impairment in multiple sclerosis - a review of current knowledge and recent research. Rev Neurosci. 2017 Nov 27;28(8):845-60. https://doi.org/10.1515/revneuro-2017-0011

28. Kalb R, Beier M, Benedict RHb, Charvet L, Costello K, Feinstein A, et al. Recommendations for cognitive screening and management in multiple sclerosis care. Mult Scler. 2018 Nov;24(13):1665-80. https:// doi.org/10.1177/1352458518803785

29. Itakura M, Pu S, Ohdachi H, Matsumura H, Yokoyama K, Nagata I, et al. Association between social functioning and prefrontal cortex function during a verbal fluency task in schizophrenia: a near-infrared spectroscopic study. Psychiatry Clin Neurosci. 2017 Nov;71(11):769-79. https://doi.org/10.1111/pcn.12548

30. Henry A, Tourbah A, Chaunu M-P, Bakchine S, Montreuil M. Social cognition abilities in patients with different multiple sclerosis subtypes. J Int Neuropsychol Soc. 2017 Sep;23(8):653-64. https://doi. org/10.1017/S1355617717000510

31. Förster K, Jörgens S, Air TM, Bürger C, Enneking V, Redlich R, et al. The relationship between social cognition and executive function in major depressive disorder in high-functioning adolescents and young adults. Psychiatry Res. 2018 May;263:139-46. https://doi. org/10.1016/j.psychres.2018.02.046

32. Neuhaus M, Bagutti S, Yaldizli Ö, Zwahlen D, Schaub S, Frey B, et al. Characterization of social cognition impairment in multiple sclerosis. Eur J Neurol. 2018 Jan;25(1):90-6. https://doi.org/10.1111/ene.13457

33. Białecka-Pikul M, Kołodziejczyk A, Bosacki S. Advanced theory of mind in adolescence: do age, gender and friendship style play a role? J Adolesc. 2017 Apr;56:145-56. https://doi.org/10.1016/j. adolescence.2017.02.009

34. Kuhnert R-L, Begeer S, Fink E, de Rosnay M. Gender-differentiated effects of theory of mind, emotion understanding, and social preference on prosocial behavior development: a longitudinal study. J Exp Child Psychol. 2017 Feb;154:13-27. https://doi.org/10.1016/j. jecp.2016.10.001 